\title{
Obituary
}

\section{Frederic M Quitkin}

Neuropsychopharmacology (2006) 31, 890. doi: | 0.1038/sj.npp. 1301017

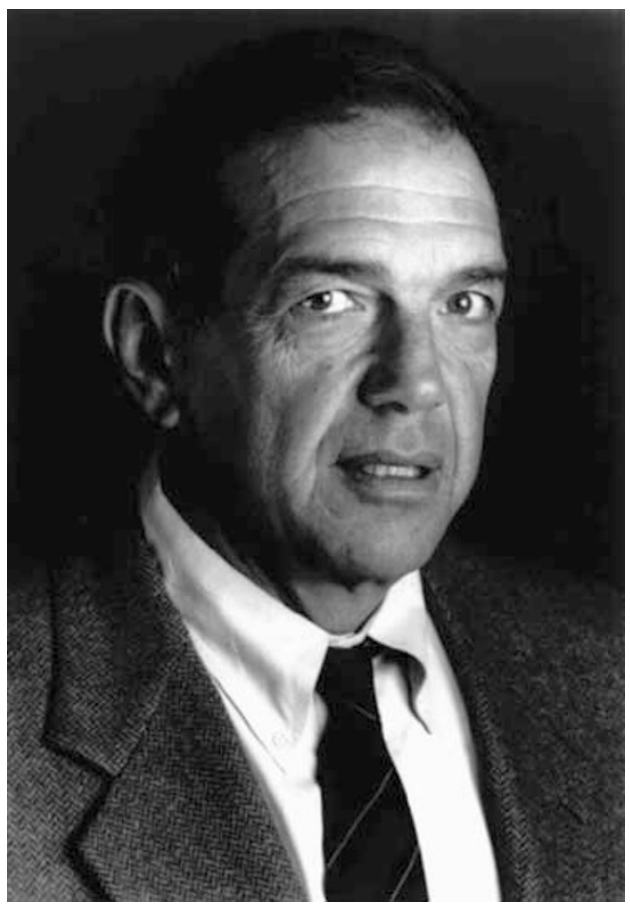

Dr Frederic Quitkin, aged 68 years, died in New York City on October 9, 2005 of pancreatic cancer, for which he had been in treatment for over 1 year. The Department of Psychiatry of the College of Physicians and Surgeons of Columbia University and the staff of the New York State Psychiatric Institute are profoundly saddened by the passing our long-time Director of the Depression Evaluation Service. We lost a unique friend and colleague of complete integrity and enormous energy, dedicated to the development of scientific treatment for those suffering from psychiatric disorders.

After graduating from Princeton University and the State University of New York Health Science Center at Brooklyn, better known as Downstate Medical Center, Fred Quitkin began his career in psychiatric research at Hillside Hospital. Mentored in psychiatric research by Donald F Klein MD, with whom he formed a lifelong collaboration, he focused on discovering and evaluating rational treatments for depression, anxiety, substance abuse, and schizophrenia. This partnership produced the innovative text, Diagnosis and Drug treatment of Psychiatric Disorders, with Rachel Klein PhD and Arthur Rifkin MD. After receiving his Doctor of Medical Science Degree at Downstate, he continued pioneering work in psychopharmacology by describing the social and cognitive deficits of patients with schizophrenia.
Dr Quitkin's pioneering report of subtle neurologic impairments in people with schizophrenia was dramatically ahead of its time, showing that what was then thought to be a disorder psychologically induced by defective parenting, was actually the result of disordered structure and function in the central nervous system. He documented the destructive effects of long-term hospitalization for nonpsychotic psychiatric disorders and the often dramatic therapeutic benefits of the revolutionary new medications for psychiatric illness.

Moving to the New York State Psychiatric Institute and Columbia University in 1977, he continued his dynamic research efforts by forming the Depression Evaluation Service, dedicated to research in depressive disorders. In collaboration with colleagues, his clinical research delineated the specific syndrome of atypical depression, now accepted by the official diagnostic nomenclature. These studies showed for the first time that rational selection of an antidepressant medication was possible based on clinical features. Further work showed the effects of antidepressant treatment on depressive disorders seen in the course of alcohol and drug dependence, the characteristics of placebo and the specific true pharmacologic responses to medication (a technical tour de force), and innovative studies combining antidepressants to more rapidly relieve suffering from these devastating disorders.

Dr Quitkin was active in multiple psychiatric research and clinical organizations, including, the American College of Neuropsychopharmacoloy, the Collegium Internationale Neuropsychopharmacologicum, the American Psychiatric Association and he was Past President of the Psychiatric Research Society. Dr Quitkin's mentored many psychiatric researchers who pursued and extended his pioneering, imaginative, ideas. $\mathrm{He}$ was always a tireless clinical psychopharmacologist, never daunted by the most complex and difficult psychiatric disorders, and always freely available to his many grateful patients for psychologic support and vigorous pharmacologic treatment. Recovery of full emotional health for his patients was ever his goal. His dedication and perseverance set an inspiring example for the pursuit of excellence in clinical research and therapeutic care.

Fred Quitkin was an avid and expert skier who enjoyed skiing Utah powder at the meeting of the Psychiatric Research Society and skiing in Switzerland and France whenever possible. His competitiveness on the tennis court was also well demonstrated at all the psychiatric meetings he attended. A lifelong Francophile, Fred's favorite travel destination was southern France, where he greatly enjoyed the art museums and French cuisine. Fred is survived by his son Dr Matthew Quitkin, a hand surgeon, and his daughters Rachel Quitkin, an attorney, and Megan Quitkin, a freelance writer. 